\title{
Epidemiological and clinical characteristics of healthcare-associated infection in elderly patients in a large Chinese tertiary hospital: a 3-year surveillance study
}

Xia Zhao ${ }^{1}$, Lihong Wang ${ }^{1 *}$, Nan Wei ${ }^{2}$, Jingli Zhang ${ }^{1}$, Wenhui Ma' ${ }^{1}$, Huijie Zhao ${ }^{1}$ and Xu Han ${ }^{1}$

\begin{abstract}
Background: We analyzed the results of a 3-year surveillance study on the epidemiological and clinical characteristics of healthcare associated-infections (HAls) in elderly inpatients in a large tertiary hospital in China.

Methods: Real-time surveillance was performed from January 1, 2015 to December 31, 2017. All HAls were identified by infection control practitioners and doctors. Inpatient data were collected with an automatic surveillance system.

Results: A total of 134,637 inpatients including 60,332 (44.8\%) elderly $\geq 60$ years were included. The overall incidence of HAl was $2.0 \%$. The incidence of $\mathrm{HAl}$ in elderly patients was significantly higher than that in non-elderly patients $\left(2.6 \%\right.$ vs. $\left.1.5 \%, X^{2}=202.421, P<0.01\right)$ and increased with age. The top five sites of HAls in the elderly were the lower respiratory tract, urinary tract, blood stream, antibiotic-associated diarrhea, and surgical site. The five most common pathogens detected in elderly HAl patients were Candida albicans, Klebsiella pneumonia, Acinetobacter baumannii, Escherichia coli, and Pseudomonas aeruginosa. The incidence of ventilator-associated pneumonia in the elderly was lower than in the non-elderly, catheter-associated urinary tract infections were more common in elderly patients, and the rate of central line-associated bloodstream infection was similar between groups. The numbers of male patients and patients with comorbidities and special medical procedures (e.g., intensive care unit admission, cerebrovascular disease, brain neoplasms, hypertension, hyperlipidemia, diabetes mellitus, coronary artery disease, chronic obstructive pulmonary disease, malignant tumor, malignant hematonosis, and osteoarthropathy) were significantly higher in the elderly group, but the number of patients who underwent surgery was lower.

Conclusion: We observed a significantly higher overall incidence of HAl in elderly inpatients $\geq 60$ compared to non-elderly inpatients $<60$ years, but the trend was different for device-associated HAls, which was attributed to the higher rates of comorbidities and special medical procedures in the elderly group. The main HAI sites in elderly inpatients were the lower respiratory tract, urinary tract, and bloodstream, and the main pathogens were gramnegative bacilli and Candida albicans.
\end{abstract}

Keywords: Healthcare associated-infection, Elderly, Ventilator-associated pneumonia, Catheter-associated urinary tract infection, Central line-associated bloodstream infections, Pathogens

\footnotetext{
*Correspondence: j_window@163.com

${ }^{1}$ Hospital Infection Management Division, Xuanwu Hospital, Capital Medical

University, No.45 Changchun Street, Xicheng District, Beijing 100053, China

Full list of author information is available at the end of the article
}

(c) The Author(s). 2020 Open Access This article is distributed under the terms of the Creative Commons Attribution 4.0 International License (http://creativecommons.org/licenses/by/4.0/), which permits unrestricted use, distribution, and reproduction in any medium, provided you give appropriate credit to the original author(s) and the source, provide a link to the Creative Commons license, and indicate if changes were made. The Creative Commons Public Domain Dedication waiver (http://creativecommons.org/publicdomain/zero/1.0/) applies to the data made available in this article, unless otherwise stated. 


\section{Background}

Modern societies have continually growing numbers of elderly inpatients. In 2017, there were an estimated 962 million people aged $\geq 60$ years in the world, comprising $13 \%$ of the global population [1]. The population aged $\geq 60$ is growing at an annual rate of $\sim 3 \%$. European countries currently have the greatest percentage of population aged $\geq 60$ (25\%). Rapid ageing will also soon occur in other parts of the world, and by 2050 all regions except Africa will have nearly a quarter or more of their populations $\geq 60$ [1]. Population ageing is projected to have a profound effect on societies by increasing demand on fiscal, political, healthcare, and social protection systems of many countries in coming decades. China will be one of the countries affected.

Healthcare associated-infections (HAIs) occur in patients under medical care in hospitals or other healthcare facilities. These infections occur during healthcare delivery for other diseases and even after discharge. HAIs are associated with prolonged hospital stay, poor prognosis, and increased mortality and economic burden [2-4]. A systematic review and meta-analysis reported that the major risk factors independently associated with HAIs were diabetes mellitus, immunosuppression, body temperature, surgery time in minutes, reoperation, cephalosporin exposure, days of exposure to central venous catheter, intensive care unit (ICU) admission, ICU stay in days, and mechanical ventilation [5]. Moreover, invasive devices such as catheters, ventilators, and central lines are associated with HAIs. The elderly are particularly vulnerable to infections due to reduced immunological competence and a high risk of underlying chronic illness [6-10]. However, there are limited data available regarding HAIs in elderly inpatients. Here we describe and analyze the results of a 3-year real-time surveillance study on the incidence of HAIs and the epidemiological and clinical characteristics of elderly inpatients in a large tertiary hospital in China.

\section{Methods}

A cohort study based on real-time surveillance was performed from January 1, 2015 to December 31, 2017 in a large tertiary hospital with 1147 beds in Beijing, China. We carried out real-time surveillance of HAIs with an online nosocomial infection surveillance system (NISS) that can download inpatients' clinical information and screen potential HAIs at any time and run automatically at an appointed time every day. Pediatric patients $\leq 14$ years and patients who had been hospitalized for $<2$ days or $>60$ days were excluded.

All HAIs that occurred during hospitalization were identified by infection control practitioners and doctors. HAIs were defined as infections that occurred $48 \mathrm{~h}$ after the patients were admitted to hospital according to the
2001 definitions published by Ministry of Health of the People's Republic of China [11]. We implement postdischarge surveillance of surgical site infection (SSI) for patients who undergo surgery. SSI included infection that occurred within 30 days after the procedure if no implant is left in place or within 1 year if an implant is placed.

The data were collected using an automatic online real-time NISS (RT-NISS, VERSION:12.8.2.1). The RTNISS downloads and records clinical information for each participant including demographic characteristics, hospitalization days, diagnoses, operations, specific device days, body temperature, laboratory and auxiliary examinations, microbiologic profile, and bacterial resistance automatically online from other information systems including the hospital information system, electronic medical record, laboratory information system, picture archiving and communication system, mobile nursing information system, and anesthesia operation system. Then the RT-NISS automatically screens potential HAIs according to the 2001 definitions published by the Ministry of Public Health, which are input into the system by the algorithm of fever history, microbiological reports, serological and molecular testing, radiology information, and antibiotic usage [12].

The infection control team checked the collected data and removed invalid inputs. Then the infection control practitioners and doctors identified potential HAIs screened by RT-NISS according to the 2001 definitions published by Ministry of Health of the People's Republic of China. This ensured that the collected data were valid and reliable. Previous studies showed that compared with a manual survey of HAIs (the gold standard) in all inpatients, the sensitivity and specificity of RT-NISS were 98.8 and $93.0 \%$, respectively [12].

\section{Data analysis}

SPSS 17.0 (SPSS Inc., Chicago, IL, USA) and Stata 9.0 (StataCorp, College Station, TX, USA) were used for data analysis. Rate ratios (RRs), 95\% confidence intervals (CIs), and $P$ values were calculated to identify significant differences in incidence density. Differences in categorical variables were assessed using $X^{2}$ tests. Statistical testing was performed at the conventional 2-tailed $\alpha=0.05$.

\section{Results \\ Study population}

During the 3-year study period, a total of 134,637 admissions with a total of 1,196,912 hospital days were involved in the study, including 60,332 (44.8\%) elderly inpatients $\geq 60$ years with 572,485 hospital days. The median hospital stay length was 7 days in total and 8 days in elderly. The median ages overall and for elderly were 58 and 69 years, respectively. 


\section{HAls in elderly and non-elderly patients}

There were 2712 HAI cases among the 134,637 included patients with $1,196,912$ patient-days, and the total incidence and incidence density of HAI were $2.0 \%$ and 2.3 per 1000 patient-days, respectively. The incidence density of HAI in elderly patients was significantly higher than in non-elderly under 60 years old and increased with age (Table 1). There were 1580 HAIs in 60,332 elderly inpatients and 1132 HAIs in 74,305 non-elderly inpatients, with a significantly higher incidence in elderly compared to non-elderly $\left(2.6 \%\right.$ vs. $1.5 \%, X^{2}=202.421$, $P<0.001)$. The incidence of HAI in elderly inpatients significantly increased with age, with rates of $2.0 \%$ (637/ $32,156), 2.5 \%$ (462/18,203), and 4.8\% (481/9973), respectively in patients aged 60-69 years, 70-79 years and $\geq 80$ years $\left(\chi^{2}=225.960, P<0.001\right)$. The four departments with the highest HAI incidence rates were hematology and gerontology in the medicine department and the vascular and general surgical departments: 10.8, $6.5,4.3$, and $3.2 \%$ respectively. The departments with the lowest HAI incidence were otorhinolaryngology, gynecology and obstetrics, pain, and ophthalmology with $0.9,0.5,0.4$, and $0.03 \%$, respectively.

The ventilator and central line use rates in elderly patients were significantly higher than in non-elderly patients, but the urinary catheter use rate was lower in elderly patients. The incidence of ventilator-associated pneumonia (VAP) in elderly patients was lower than in non-elderly patients, catheter-associated urinary tract infections (CAUTIs) were significantly more common in elderly patients, and central line-associated bloodstream infection (CLABSI) rates were similar in both groups (Tables 2 and 3).

\section{The main sites of HAls in elderly patients}

The top three sites of HAIs in elderly were the lower respiratory tract, urinary system, and bloodstream. Among these three sites, the rates of VAP, CAUTI, and CLABSI were $7.1 \%$ (57/802), 61.4\% (170/277), and 33.3\% (90/ 270), respectively (Table 4 ).

\section{Comorbidities and special medical procedures}

The numbers of male patients and patients with comorbidities and special medical procedures (e.g., neurological and chronic noncommunicable diseases and ICU admission) were significantly higher in the elderly, but fewer patients in that group underwent surgery (Table 5).
The main pathogens detected in elderly HAI patients The top five pathogens detected in elderly HAI patients were Candida albicans, Klebsiella pneumonia, Acinetobacter baumannii, Escherichia coli, and Pseudomonas aeruginosa. However, the main pathogens differed by infection site (Table 6).

\section{Discussion}

Analysis of 3 years of data showed that the incidence and incidence density of HAIs in elderly patients were significantly higher than in non-elderly patients $(2.6 \%$ vs. $1.5 \%, 2.8 / 1000 \mathrm{~d}$ vs. $1.8 / 1000 \mathrm{~d}, P<0.05)$. The incidence of HAIs in the oldest group ( $\geq 80$ years) was three-fold higher than that in non-elderly $(4.8 \%$ vs. $1.5 \%, P<0.05)$. Although the incidence of HAIs in this study was lower than most previous publications, the trend was consistent. HAIs accounts for 3.5-9\% of all infections in developed and developing countries [13]. Extensive studies in the USA and Europe showed that HAI incidence density ranged from 13.0 to 20.3 episodes per 1000 patient-days [14]. Incidence rates are higher in ICUs, affecting 30\% of patients [15]. However, a survey of long-term care facilities for the elderly in Japan found that the overall incidence rate of HAIs was 0.18 per 1000 resident-days [16]. A survey of the prevalence of HAIs in older people in acute care hospitals in Scotland found a linear relationship between HAI prevalence and increasing age, the incidence of HAIs in patients younger and older than 65 were 7.37 and $11.13 \%$, respectively [13]. An investigation of the HAI incidence in elderly hospitalized patients at a hospital in Hunan Province, China reported that the HAI incidence in patients aged $\geq 65$ was significantly higher than in those aged $<65\left(3.53 \%\right.$ vs. $0.98 \%, X^{2}=$ $354.44, P<0.001)$ [17]. We may have underestimated the HAI incidence because we did not implement postdischarge surveillance for all inpatients. The lower HAI incidence may also be related to the shorter average hospital stay. In this study, the median lengths were only 7 days overall and 8 days for elderly patients.

Elderly inpatients are at high risk of HAI because of their poor immune function, decreased mobility, and comorbid chronic noncommunicable diseases such as cardiovascular disease, cancer, diabetes, and chronic obstructive pulmonary disease (COPD). Furthermore, elderly inpatients with HAIs have poor prognosis and increased economic burden [18]. One study evaluated elderly patients who had an HAI in the ICU and found that clinical outcomes of the elderly who acquired an

Table 1 Comparison of HAl incidence density in elderly and non-elderly patients

\begin{tabular}{lllllll}
\hline & Patient days & No. of HAls & Incidence density (per 1000 patient-days) & $\mathrm{RR}$ & $95 \% \mathrm{Cl}$ & $P$ \\
\hline Elderly $(\geq 60 \mathrm{y})$ & 572,485 & 1580 & 2.8 & 1.530 & $1.422-1.651$ \\
Non-elderly $(<60 \mathrm{y})$ & 624,427 & 1126 & 1.8 & & $<0.001$ \\
\hline
\end{tabular}

$\mathrm{Cl}$ confidence interval, $R R$ rate ratio 
Table 2 Comparison of the device use rates in elderly and non-elderly patients

\begin{tabular}{|c|c|c|c|c|c|c|}
\hline \multirow[t]{2}{*}{ Device } & \multicolumn{2}{|c|}{$\begin{array}{l}\text { Elderly ( } \geq 60 \text { years) } \\
N=60,332\end{array}$} & \multicolumn{2}{|c|}{$\begin{array}{l}\text { Non-elderly (<60 years) } \\
N=74,305\end{array}$} & \multirow[t]{2}{*}{$x^{2}$} & \multirow[t]{2}{*}{$P$} \\
\hline & No. of use & Use rate\% & No. of use & Use rate\% & & \\
\hline Ventilator & 1854 & 3.1 & 1544 & 2.1 & 134.015 & $<0.001$ \\
\hline Central line & 3994 & 6.6 & 4103 & 5.5 & 71.046 & $<0.001$ \\
\hline Urinary catheter & 16,376 & 27.1 & 20,577 & 27.7 & 5.048 & 0.025 \\
\hline
\end{tabular}

infection in the ICU were influenced by sociodemographic and clinical variables that increase mortality rates [19]. Another study of HAI in elderly patients identified the following risk factors: advanced age; comorbid neurological and chronic noncommunicable diseases such as cerebral hemorrhage, cerebral infarction, brain neoplasms, diabetes mellitus, coronary artery disease, malignant tumor and malignant hematonosis; hospital days before HAI; ICU admission; and device use [9]. The participants of that study were elderly $\geq 60$ years with or without HAIs. To control for confounders and identify novel risk factors of HAI in this population, we investigated comorbidities and special medical procedures in elderly and non-elderly groups. The percentages of male patients, patients with comorbidities (e.g., cerebrovascular disease, brain neoplasms, hypertension, hyperlipidemia, diabetes mellitus, coronary artery disease, COPD, malignant tumor, malignant hematonosis, and osteoarthropathy), and ICU admissions were significantly higher in the elderly group. Conversely, fewer elderly patients underwent surgery lower. These results suggest that the higher incidence of HAI in elderly may be attributable to the higher rates of comorbidities and special medical procedures in elderly inpatients.

One of the primary concerns of the current investigation was identifying common HAIs sites in elderly inpatients. Most HAIs were found in the lower respiratory tract, urinary system, and bloodstream. These findings are consistent with other available studies of both elderly and non-elderly inpatients $[11,20]$. With recent improvements in implants, it is important to focus on device-associated infections (DAIs). The International
Nosocomial Infection Control Consortium (INICC) and National Healthcare Safety Network reported monitoring data of HAIs in general and DAIs in particular. The INICC recorded the data of 861,284 patients hospitalized in INICC hospital ICUs in 50 countries for an aggregate of 3,506,562 days from 2010 to 2015. There were 6.219.2 cases of VAP per 1000 mechanical ventilator-days, 1.44-10.14 CLABSIs per 1000 central line-days, and 1.66-17.17 CAUTIs per 1000 catheter-days [21].

For elderly inpatients with lower respiratory tract, urinary system, and bloodstream infections, the percentages of VAP, CAUTI, and CLABSI were 7.1\% (57/802), $61.4 \%$ (170/277), and 33.3\% (90/270), respectively. Ventilator and central line use rates in the elderly group were significantly higher than in the non-elderly, but the elderly had a lower urinary catheter use rate. The incidence density of VAP in elderly was lower than in non-elderly, but CAUTIs were significantly higher, and CLABSI rates were similar. These results suggest that the incidence densities of VAP, CLABSI, and CAUTI in elderly inpatients did not increase with the ventilator, central line, and urinary catheter use rates. The lower incidence density of VAP in the elderly group was probably because the admitting diagnosis often included lower respiratory tract infections, and it was difficult to find evidence of VAP in these patients. The high incidence density of CAUTI in elderly inpatients is consistent with other reports. A study concerned with risk factors for CAUTI in Italian elderly found that increasing age and duration of hospital stay before catheter insertion were associated with CAUTIs [22]. The high percentage of CAUTI may be related to specific issues of elderly

Table 3 Comparison of the incidence densities of HAls in elderly and non-elderly patients

\begin{tabular}{|c|c|c|c|c|c|c|c|c|c|}
\hline \multirow[t]{2}{*}{ Variable } & \multicolumn{3}{|c|}{ Elderly ( $\geq 60$ years) } & \multicolumn{3}{|c|}{ Non-elderly (<60 years) } & \multirow[t]{2}{*}{ RR } & \multirow[t]{2}{*}{$95 \% \mathrm{Cl}$} & \multirow[t]{2}{*}{$P$} \\
\hline & $\begin{array}{l}\text { No. of } \\
\text { cases }\end{array}$ & $\begin{array}{l}\text { Ventilator/central line/ } \\
\text { urinary catheter days }\end{array}$ & $\begin{array}{l}\text { Incidence density } \\
\text { (per } 1000 \text { days) }\end{array}$ & $\begin{array}{l}\text { No. of } \\
\text { cases }\end{array}$ & $\begin{array}{l}\text { Ventilator/central line/ } \\
\text { urinary catheter days }\end{array}$ & $\begin{array}{l}\text { Incidence density } \\
\text { (per } 1000 \text { days) }\end{array}$ & & & \\
\hline VAP & 57 & 15,379 & 3.7 & 76 & 9899 & 7.7 & 0.483 & $\begin{array}{l}0.345- \\
0.676\end{array}$ & 0.001 \\
\hline CLABSI & 90 & 39,372 & 2.3 & 75 & 32,561 & 2.3 & 0.992 & $\begin{array}{l}0.730- \\
1.348\end{array}$ & 0.959 \\
\hline CAUTI & 170 & 81,760 & 2.1 & 100 & 62,335 & 1.6 & 1.296 & $\begin{array}{l}1.013- \\
1.658\end{array}$ & 0.038 \\
\hline
\end{tabular}


Table $4 \mathrm{HAl}$ sites in the elderly

\begin{tabular}{lll}
\hline HAls site & Infection cases & Percentage \% \\
\hline Lower respiratory tract infections & 802 & 42.7 \\
Pneumonia (non-VAP) & 571 & 30.4 \\
Tracheobronchitis & 174 & 9.3 \\
VAP & 57 & 3.0 \\
Urinary system infections & 277 & 14.7 \\
Non-CAUTI & 107 & 5.7 \\
CAUTI & 170 & 9.0 \\
Blood stream infections & 270 & 14.4 \\
Non-CLABSI & 180 & 9.6 \\
CLABSI & 90 & 4.8 \\
Digestive system infections & 189 & 10.1 \\
Antibiotic-associated diarrhea & 121 & 6.4 \\
Others & 68 & 3.6 \\
Surgical site infections & 68 & 3.6 \\
Skin and soft tissue infections & 49 & 2.6 \\
Upper respiratory tract infections & 40 & 2.1 \\
Oral infections & 34 & 1.8 \\
Central nervous system infections & 31 & 1.7 \\
Other infections & 120 & 6.4 \\
Total & 1880 & 100.0 \\
\hline A & &
\end{tabular}

CAUTI catheter-associated urinary tract infection, CLABSI central line-associated bloodstream infection, HAls healthcare associated-infections, VAP ventilator-associated pneumonia inpatients, but also due to failures in catheter insertion as we observed here and which may be our next study. The low similar incidence density of CLABSI in both the elderly and non-elderly groups may be related to effective interventions to prevent CLABSI. Hallam and colleagues collected data over a 5-year period and found a significant and sustained reduction in the CLABSI rate from 5 per 1000 catheter days to 0.23 per 1000 catheter days [23].

The other notable finding of the current investigation was the pathogens detected in elderly HAI patients. The five most common were Candida albicans, Klebsiella pneumonia, Acinetobacter baumannii, Escherichia coli, and Pseudomonas aeruginosa, but they varied by infection site. Extensive use of broad-spectrum antibiotics in elderly could account for the high positive detection rate of Candida albicans. The main pathogens of lower respiratory tract, urinary system, and bloodstream infections detected in elderly HAI patients could serve as reference evidence for empirical use of antibiotics to treat HAIs.

\section{Study limitations}

First, this was a single-center study, so our findings cannot be generalized to all elderly patients in China. Second, we may have underestimated the HAI incidence because we did not implement post-discharge surveillance for all inpatients. Finally, the microorganism profile did not include drug sensitivity or antibiotic

Table 5 Comparison of the comorbidities and medical procedures in elderly and non-elderly

\begin{tabular}{|c|c|c|c|c|c|c|}
\hline \multirow[t]{2}{*}{ Variables } & \multicolumn{2}{|l|}{$\begin{array}{l}\text { Elderly } \\
(\geq 60 \text { years }) \\
N=60,332\end{array}$} & \multicolumn{2}{|c|}{$\begin{array}{l}\text { Non-elderly (< } 60 \text { years) } \\
N=74,305\end{array}$} & \multirow[t]{2}{*}{$x^{2}$} & \multirow[t]{2}{*}{$P$} \\
\hline & No. of cases & $\%$ & No. of cases & $\%$ & & \\
\hline \multicolumn{7}{|l|}{ Sex } \\
\hline Male & 33,280 & 55.2 & 34,293 & 46.2 & 1081.172 & $<0.001$ \\
\hline Female & 27,052 & 44.8 & 40,012 & 53.8 & & \\
\hline ICU admission & 8352 & 13.8 & 7507 & 10.1 & 448.296 & $<0.001$ \\
\hline Operation & 27,705 & 45.9 & 36,762 & 49.5 & 168.488 & $<0.001$ \\
\hline Cerebral hemorrhage & 2770 & 4.6 & 3113 & 4.2 & 12.863 & $<0.001$ \\
\hline Cerebral infarction & 19,779 & 32.8 & 11,350 & 15.3 & 5742.483 & $<0.001$ \\
\hline Brain neoplasms & 444 & 0.7 & 269 & 0.4 & 88.371 & $<0.001$ \\
\hline Hypertension & 34,050 & 56.4 & 17,931 & 24.1 & $14,661.554$ & $<0.001$ \\
\hline Hyperlipidemia & 8453 & 14.0 & 7424 & 10.0 & 517.187 & $<0.001$ \\
\hline Diabetes mellitus & 18,885 & 31.3 & 11,827 & 15.6 & 4476.053 & $<0.001$ \\
\hline Coronary artery disease & 18,352 & 30.4 & 5871 & 7.9 & $11,442.063$ & $<0.001$ \\
\hline COPD & 2126 & 3.5 & 302 & 0.4 & 1827.284 & $<0.001$ \\
\hline Malignant tumor & 10,409 & 17.3 & 8011 & 10.8 & 1180.859 & $<0.001$ \\
\hline Malignant hematonosis & 2513 & 4.2 & 1922 & 2.6 & 260.489 & $<0.001$ \\
\hline Osteoarthropathy & 3207 & 5.3 & 2523 & 3.4 & 301.271 & $<0.001$ \\
\hline
\end{tabular}


Table 6 Most common pathogens detected in elderly HAl patients

\begin{tabular}{|c|c|c|}
\hline HAl site & Pathogen & Strain (percentage \%) \\
\hline \multirow[t]{7}{*}{ Lower respiratory tract } & Acinetobacter baumannii & $90(18.0)$ \\
\hline & Candida albicans & $88(17.6)$ \\
\hline & Klebsiella pneumoniae & $71(14.2)$ \\
\hline & Pseudomonas aeruginosa & $55(11.0)$ \\
\hline & Stenotrophomonas maltophilia & $37(7.4)$ \\
\hline & Others & 158(31.7) \\
\hline & Subtotal & 499(100.0) \\
\hline \multirow[t]{7}{*}{ Urinary system } & Candida albicans & $55(24.4)$ \\
\hline & Escherichia coli & $39(17.3)$ \\
\hline & Enterococcus faecium & $36(16.0)$ \\
\hline & Candida tropicalis & 20(8.9) \\
\hline & Klebsiella pneumoniae & $17(7.6)$ \\
\hline & Others & $58(25.8)$ \\
\hline & Subtotal & $225(100.0)$ \\
\hline \multirow[t]{8}{*}{ Blood stream } & Escherichia coli & $39(13.2)$ \\
\hline & Klebsiella pneumoniae & $32(10.9)$ \\
\hline & Staphylococcus epidermidis & $20(6.8)$ \\
\hline & Enterococcus faecium & $20(6.8)$ \\
\hline & Staphylococcus hominis & $17(5.8)$ \\
\hline & Staphylococcus aureus & $12(4.1)$ \\
\hline & Others & $155(52.5)$ \\
\hline & Subtotal & 295(100.0) \\
\hline \multirow[t]{7}{*}{ Other } & Escherichia coli & 13(12.2) \\
\hline & Klebsiella pneumoniae & $10(9.4)$ \\
\hline & Acinetobacter baumannii & $7(6.5)$ \\
\hline & Staphylococcus aureus & $7(6.5)$ \\
\hline & Pseudomonas aeruginosa & $6(5.6)$ \\
\hline & Others & $64(59.8)$ \\
\hline & Subtotal & $107(100.0)$ \\
\hline \multirow[t]{7}{*}{ Total } & Candida albicans & $166(14.7)$ \\
\hline & Klebsiella pneumoniae & 130(11.6) \\
\hline & Acinetobacter baumannii & $121(10.8)$ \\
\hline & Escherichia coli & 108(9.6) \\
\hline & Pseudomonas aeruginosa & $87(7.7)$ \\
\hline & Others & $514(45.7)$ \\
\hline & Subtotal & $1126(100.0)$ \\
\hline
\end{tabular}

HAl healthcare-associated infection

resistance. We will include those tests in our next study to better prevent HAIs in elderly inpatients.

\section{Conclusions}

We observed a significantly higher overall incidence of HAIs for inpatients $\geq 60$ years old compared to those under 60 , which was attributable to higher rates of comorbidities, special medical procedures to treat neurological and chronic noncommunicable diseases, ICU admission, and surgery in elderly. The main sites of
HAIs in elderly patients were the lower respiratory tract, urinary system, and bloodstream due to high rates of VAP, CLABSI and CAUTI. Interestingly, the incidence density of device-associated infections did not increase with the higher device use rate in the elderly group. Futures studies to identify risks factors of HAIs in elderly will help decrease the rate in elderly inpatients.

\section{Abbreviations \\ CAUTI: Catheter-associated urinary tract infection; Cl: Confidence interval; CLABSI: Central line-associated bloodstream infections; HAl: Healthcare- associated infections; ICU: Intensive care unit; NISS: Nosocomial infection surveillance system; VAP: Ventilator-associated pneumonia}

\section{Acknowledgements}

We thank the many healthcare professionals who assisted with the surveillance study in our hospital.

\section{Authors' contributions}

$X Z$ contributed to implementation of the investigation, data analysis, and manuscript drafting; LHW designed and organized the study. NW and JLZ assisted with data analysis; WHM, HJZ, and XH contributed to data collection. All authors have read and approved the manuscript.

\section{Funding}

This study was funded by a Scientific Research and Cultivation Program Foundation in Beijing China (No. PG2019018) grant from Beijing Hospitals Authority and Xuanwu Hospital, Capital Medical University.

\section{Availability of data and materials}

The datasets generated and/or analyzed during the current study are not publicly available due the data copyright protection of the author's institute, but are available from the corresponding author on reasonable request.

\section{Ethics approval and consent to participate}

The study design was approved by the ethics review board of Xuanwu Hospital, Capital Medical University. The director of the Hospital Infection Management Division and the director of the information center of Xuanwu Hospital at Capital Medical University grant permission to access the raw data of the study.

\section{Consent for publication}

Not applicable.

\section{Competing interests}

The authors declare that they have no competing interests.

\section{Author details}

${ }^{1}$ Hospital Infection Management Division, Xuanwu Hospital, Capital Medical University, No.45 Changchun Street, Xicheng District, Beijing 100053, China. ${ }^{2}$ School of Health Management and Education, Capital Medical University, Beijing, China.

Received: 27 March 2019 Accepted: 31 January 2020

Published online: 10 February 2020

\section{References}

1. World population prospects: the 2017 revision, key findings and advance tables. https://reliefweb.int/report/world/world-population-prospects-2017revision-key-findings-and-advance-tables. Accessed 05 Mar 2018.

2. Kritsotakis El, Kontopidou F, Astrinaki E, Roumbelaki M, loannidou E, Gikas A. Prevalence, incidence burden, and clinical impact of healthcare-associated infections and antimicrobial resistance: a national prevalent cohort study in acute care hospitals in Greece. Infect Drug Resist. 2017;10:317-28.

3. Graves N, Weinhold D, Tong E, Birrell F, Doidge S, Ramritu P, et al. Effect of healthcare-acquired infection on length of hospital stay and cost. Infect Control Hosp Epidemiol. 2007;28(3):280-92.

4. Vrijens F, Hulstaert F, Devriese S, van de Sande S. Hospital-acquired infections in Belgian acute-care hospitals: an estimation of their global 
impact on mortality, length of stay and healthcare costs. Epidemiol Infect. 2012;140(1):126-36.

5. Rodríguez-Acelas AL, de Abreu AM, Engelman B, Cañon-Montañez W. Risk factors for health care-associated infection in hospitalized adults: systematic review and meta-analysis. Am J Infect Control. 2017;45:e149-56.

6. Llopis F, Ferré C, García-Lamberechts EJ, Martínez-Ortiz-de-Zárate M, Jacob J, González-Del-Castillo J, et al. Are short-stay units an appropriate resource for hospitalising elderly patients with infection? Rev Calid Asist. 2016;31:322-8.

7. Kemp M, Holt H, Holm A, Kolmos HJ. Elderly patients are at high risk from hospital-acquired infection. Ugeskr Laeger. 2013;18(175):2874-6.

8. Yahav D, Eliakim-Raz N, Leibovici L, Paul M. Bloodstream infections in older patients. Virulence. 2016;7(3):341-52.

9. Zhao X, Wang L, Wei N, Zhang J, Ma W, Zhao H, et al. Risk factors of health care-associated infection in elderly patients: a retrospective cohort study performed at a tertiary Hospital in China. BMC Geriatr. 2019;19:193-8.

10. Castle SC. Clinical relevance of age-related immune dysfunction. Clin Infect Dis. 2000;31:578-85.

11. The Ministry of Public Health. The nosocomial infections diagnosis criterion. Natl Med J China. 2001;81:314-20.

12. Du M, Xing Y, Suo J, Liu B, Jia N, Huo R, et al. Real-time automatic hospitalwide surveillance of nosocomial infections and outbreaks in a large Chinese tertiary hospital. BMC Med Inform Decis Mak. 2014;14:9.

13. Cairns S, Reilly J, Stewart S, Tolson D, Godwin J, Knight P. The prevalence of health care-associated infection in older people in acute care hospitals. Infect Control Hosp Epidemiol. 2011;32:763-7.

14. Khan HA, Baig FK, Mehboob R. Nosocomial infections: epidemiology, prevention, control and surveillance. Asian Pac J Trop Biomed. 2017;7:47882.

15. Abulhasan YB, Rachel SP, Châtillon-Angle MO, Alabdulraheem N, Schiller I, Dendukuri $\mathrm{N}$, et al. Healthcare-associated infections in the neurological intensive care unit: results of a 6 -year surveillance study at a major tertiary care center. Am J Infect Control. 2018;46:656-62.

16. Kariya N, Sakon N, Komano J, Tomono K, Iso H. Current prevention and control of health care-associated infections in long-term care facilities for the elderly in Japan. J Infect Chemother. 2018;24:347-52.

17. Wang J-J, Fan S-Y, Zhang N. Incidence of healthcare-associated infection in elderly hospitalized patients at a hospital in Hunan Province. Chin J Infect Control. 2015;14(7):489-91.

18. Kurutkan MN, Kara O, Eraslan IH. An implementation on the social cost of hospital acquired infections. Int J Clin Exp Med. 2015;8:4433-45.

19. Sousa ÁFL, Queiroz AAFLN, Oliveira LB, Moura LKB, Andrade D, Watanabe E, et al. Deaths among the elderly with ICU infections. Rev Bras Enferm. 2017; 70:733-9.

20. Ali HS, Khan FY, George S, Shaikh N, Al-Ajmi J. Epidemiology and outcome of ventilator-associated pneumonia in a heterogeneous ICU population in Qatar. Biomed Res Int. 2016;2016:8231787.

21. Rosenthal VD, Al-Abdely HM, El-Kholy AA, AlKhawaja SAA, Leblebicioglu H, Mehta $Y$, et al. International nosocomial infection control consortium report, data summary of 50 countries for 2010-2015: device-associated module. Am J Infect Control. 2016;44:1495-504.

22. Vincitorio D, Barbadoro P, Pennacchietti L, Pellegrini I, David S, Ponzio E, et al. Risk factors for catheter-associated urinary tract infection in Italian elderly. Am J Infect Control. 2014;42:898-901.

23. Hallam C, Jackson T, Rajgopal A, Russell B. Establishing catheter-related bloodstream infection surveillance to drive improvement. J Infect Prev. 2018;19:160-6

\section{Publisher's Note}

Springer Nature remains neutral with regard to jurisdictional claims in published maps and institutional affiliations.

Ready to submit your research? Choose BMC and benefit from:

- fast, convenient online submission

- thorough peer review by experienced researchers in your field

- rapid publication on acceptance

- support for research data, including large and complex data types

- gold Open Access which fosters wider collaboration and increased citations

- maximum visibility for your research: over $100 \mathrm{M}$ website views per year

At BMC, research is always in progress.

Learn more biomedcentral.com/submissions 